\title{
Novel mutations in the duplicated region of PKD1 gene
}

\author{
R Perrichot ${ }^{1,2}$, B Mercier ${ }^{2}$, I Quere ${ }^{2}$, A Carre ${ }^{2}$, P Simon ${ }^{3}$, B Whebe ${ }^{4}$, J Cledes ${ }^{1}$ and C Ferec ${ }^{2}$
}

\author{
${ }^{1}$ Service de Néphrologie; ${ }^{2}$ Laboratoire de Génétique Moléculaire, CHU and EFS-Bretagne, Brest; ${ }^{3}$ Service de \\ N éphrologie, CH, Quimper; ${ }^{4}$ Service de Néphrologie, $\mathrm{CH}$, Saint-Brieuc, France
}

\begin{abstract}
Autosomal dominant polycystic kidney disease (ADPKD) exhibits a genetically heterogeneous transmission involving at least three different genes. PKD1 gene linked mutations are responsible for the disease in about $85 \%$ of ADPKD cases. The search for mutations is a very important step in understanding the molecular mechanisms underlying ADPKD. We undertook this study using denaturing gradient gel electrophoresis (DGGE), after a stage of long range PCR, to scan for mutations in the duplicated region of the PKD1 gene in French ADPKD families. This allowed us to identify eight novel mutations and several polymorphisms: among the mutations, three are nonsense mutations, two are deletions in the coding sequence leading to frameshift mutations, one is a splice mutation and two are highly probable missense mutations. In this paper, we also provide a review of the mutations reported so far which are widespread throughout the gene. Although no clear hot spot for mutation is apparent, we will focus on some clustering observed. European Journal of Human Genetics (2000) 8, 353-359.
\end{abstract}

Keywords: PKD1; mutation; DGGE

\section{Introduction}

Autosomal dominant polycystic kidney disease (ADPKD), a common genetic renal disorder exhibits a genetically heterogeneous transmission ${ }^{1}$ with at least three different genes involved. PKD 1 gene linked mutations, located on chromosome 16p13.3, ${ }^{2}$ account for $85 \%$ of ADPKD; those in PKD2, at locus $4 q 21-23,3,4$ are responsible for the disease in about $10-15 \%$ of cases, and at least a third locus still unidentified is involved in the transmission of the disease in some reported families. $^{5}$

Whatever the gene involved in the transmission of the disease, the disorder is characterised by the progressive development of renal cysts leading to end stage renal disease (ESRD) in about $60-80 \%$ of ADPKD patients. ${ }^{6}$ However, ADPKD displays a great inter-familial phenotypic variability in the course of the disease, partly explained by the genetic heterogeneity in the transmission of the disease., 7,8 PKD 1linked disease is associated with a poorer renal prognosis than the PKD2 form: the median age at onset of ESRD was

Correspondence: Dr Perrichot, Laboratoire de Génétique Moléculaire et d'Histocompatibilité, ETSBO-CHU, 46 rue Félix Le Dantec, 29275, Brest, Cédex, France. Tel: 332984450 64; Fax: 332984305 55; E-mail: regine.perrichot@univ-brest.fr

Received 24 September 1999; revised 13 December 1999; accepted 22 December 1999 shown to be later in PKD2 than in PKD1 (74 vs 54 years) in a recent European multicentric study. ${ }^{9}$ Nevertheless, the intrafamilial phenotypic variability is not explained by the inheritance of the same stable DNA change as has been reported in families with an identified mutation. ${ }^{10,11}$ The two-hit mechanism, with a loss of heterozygosity displayed by $17-24 \%$ of the examined cysts from ADPKD1 patients, ${ }^{12,13}$ represents an alternative explanation to this phenomenon of phenotypic variability; the factors governing the rate of second hits have yet to be identified. In the same way, recently, second-hit mutations in human PKD2 cysts have been identified. ${ }^{14,16}$ The largest known polypyrimidine tract of about $2.5 \mathrm{~Kb}$ is considered partly responsible for the high mutability of the PKD 1 gene. ${ }^{12}$ The PKD1 gene segregation with other modifying genes or the role of environmental factors could be also hypothesised.

The identification of mutations is one of the most important steps towards improving our knowledge of the physiopathology of the disease. To date, about 65 mutations have been identified in the PKD1 gene $e^{2,10,17-30}$ with only four mutations reported more than once. ${ }^{17,19,21,28,31}$ Most of them are located in the non-duplicated region of the gene. Some authors have developed strategies to specifically analyse the duplicated region of the gene, ${ }^{20,23,26,32}$ using the protein- 
truncation test $(\mathrm{PTT})^{33}$ or the RNase-cleavage assay ${ }^{20}$ with or without a preliminary step of long-range PCR, which requires one specific primer located either in the duplicated area or in the non-duplicated region. However, despite intense efforts on the part of researchers, the mutation detection rate remains disappointingly low, ${ }^{23,34}$ illustrating the difficulty in correctly characterising mutations in this particular gene. In a previous study, we undertook a screening for mutations by DGGE in 146 unrelated patients within the 3 ' non-duplicated area of the gene; ${ }^{24}$ this allowed us to identify novel mutations. We have now extended our mutation screening to analyse a part of the duplicated region from the 3 ' end of exon 15 to exon 33 (except for exon 22) by the same technique.

We report here some additional novel mutations in this gene and we also provide a review of mutations reported so far.

\section{Patients and methods \\ Patients}

Our cohort of 146 unrelated ADPKD patients and the criteria for the enrolment of the patients in the study have been previously described. ${ }^{24}$ Briefly, ADPKD diagnosis was established by a nephrologist and supported by widely used criteria reported by Bear ${ }^{35}$ rather than those more recently reported by Ravine, ${ }^{36}$ in view of the fact that some blood samples and family studies were realised before 1994. For each family, pedigrees and clinical data with the age of endstage renal disease were collected.

A systematic screening of 150 normal chromosomes were performed to determine the frequency of the DNA variants in the normal population.

\section{Methods}

DNA extractions were performed according to conventional salting-out procedure. ${ }^{37}$ Two different long-range PCR amplifications of genomic DNA were performed to generate locusspecific templates as has been previously described. ${ }^{32,38}$ For these LR amplifications we used rTth DNA-polymerase-XL (Applied Biosystem, Foster City, CA, USA) according to the manufacturer's guidelines. These LR-PCRs required a single specific primer, located either in the duplicated or in the nonduplicated region. For the first LR-PCR, performed from exon 23 to exon 34, we used a specific primer located in exon 34 (e34i3 previously reported ${ }^{24}$ ) in combination with TWF1, a primer positioned in intron 22 reported previously by Watnick. ${ }^{32}$ For the second, extending from the $3^{\prime}$ end of exon 15 to exon 21, we used a PKD1 specific primer (FQF 26) located in exon 15 in combination with TWR2 in intron 21 previously reported by Watnick et al. ${ }^{38}$ The cycling parameters and the primers used in the LR-PCR are available upon request.

Internal nested PCRs were then performed exon by exon after a $10^{-5}$ fold dilution of the long-range product to avoid genomic contamination. Nested PCRs were performed in a $50 \mu \mathrm{l}$ reaction mixture containing 50 pmoles of each appropriate primer, $50 \mathrm{~mm} \mathrm{KCl}, 10 \mathrm{~mm}$ Tris- $\mathrm{HCl}(\mathrm{pH} 8.3), 10 \%$ DMSO, $200 \mu \mathrm{m}$ of each dNTP, $1.5 \mathrm{~mm} \mathrm{MgCl2}$, one unit of Taq polymerase and $1 \mu \mathrm{l}$ of diluted PCR products; 35 cycles of $30 \mathrm{~s}$ at $94^{\circ} \mathrm{C}, 30 \mathrm{~s}$ at $75^{\circ} \mathrm{C}$ and $30 \mathrm{~s}$ at $72^{\circ} \mathrm{C}$ were performed.

Sequences of the primers used for the nested PCRs are available upon request together with gradient conditions and migration times for electrophoresis. The DGGE and sequencing were performed as previously described. ${ }^{24}$ Figure 1 indicates samples displaying altered migration pattern in exon 28. Segregation analysis was performed by DGGE in the families of patients with an identified mutation.

Mutation designation The mutations described in this study were designated following the recommendations of Antonarakis. ${ }^{39}$ Nucleotides and codons were numbered according to the sequence published by Hughes ${ }^{40}$ (GenBank accession number L39891).

\section{Results}

The novel mutations reported here are summarized in Table1.

\section{7del T}

This frameshift mutation (after amino acid 3219) results from the deletion of a nucleotide $\mathrm{T}$ at position 9867 in exon 28

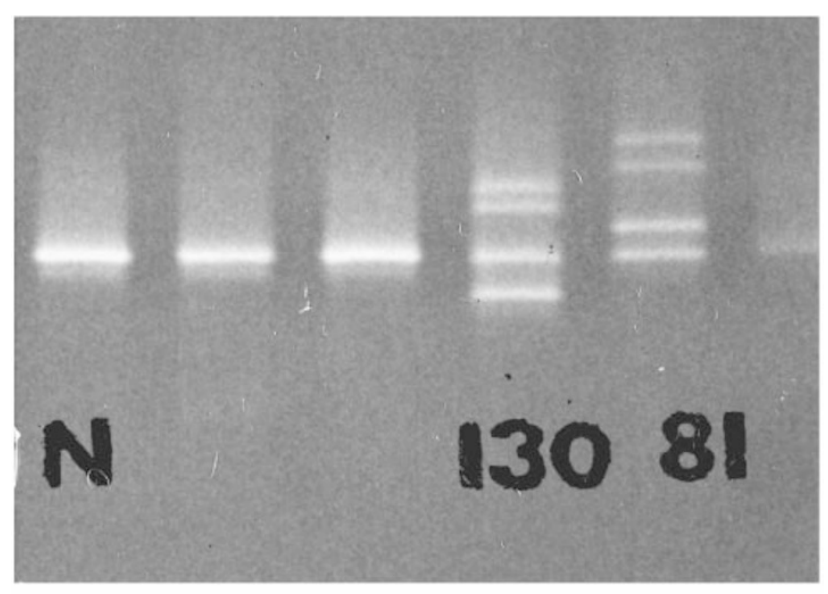

\section{Exon 28}

Figure 1 DGGE analysis of exon 28 where electrophoresis optimisation enabled the detection of two altered patterns producing homoduplex and heteroduplex band displacements. $\mathrm{N}$ corresponds to a normal allele. Patient 81: 4 bands are detected corresponding to the two heteroduplexes (upper bands), and to the two homoduplexes (lower bands). The sequencing data is Q3206X(C >t at 9827). Patient 130: the 4 bands observed correspond to the two homoduplexes (lower bands) and to the two heteroduplexes (upper bands). The sequencing data is 9867 delT. 
Table 1 Novel mutations detected in the PKD1 gene

\begin{tabular}{|c|c|c|c|}
\hline Mutation & Exon & Amino acid change & Nucleotide change \\
\hline 9867 del T & 28 & Frameshift & Del T at NT 9867 \\
\hline Q3206X & 28 & Glutamine > termination codon & $\mathrm{C} \rightarrow \mathrm{T}$ at $\mathrm{NT} 9827$ \\
\hline R2639X & 21 & Arginine $>$ termination codon & $\mathrm{C} \rightarrow \mathrm{T}$ at NT 8126 \\
\hline Y2336X & 16 & Tyrosine $>$ termination codon & $\mathrm{C} \rightarrow$ Aat NT 7219 \\
\hline $\mathrm{R} 2329 \mathrm{~W}$ & 16 & Arginine $>$ Tryptophan & $\mathrm{C} \rightarrow \mathrm{T}$ at NT 7196 \\
\hline IVS $15+2$ & 15 & Splice mutation & $\mathrm{T} \rightarrow \mathrm{G}$ at $\mathrm{NT} 7126+2$ \\
\hline T2250M & 15 & Threonine $>$ methionine & $\mathrm{C} \rightarrow \mathrm{T}$ at NT 6960 \\
\hline
\end{tabular}

(Figure2) that leads to a premature stop codon at amino acid 3315. This mutation is reported in a woman who started renal replacement therapy at 47 years of age. This DNA variant segregates with the disease, since the same abnormal DGGE pattern was found in her affected brother and was absent in her two unaffected daughters.

\section{Q3206X}

This nonsense mutation was discovered in a woman from a severely affected family with three members who reached end-stage renal failure before the age of 40 (37, 38 and 39 years). Her son of 28 years, affected by the disease, has been treated for renal failure for 2 years. This mutation is due to a modification of a $\mathrm{C}>\mathrm{T}$ at position 9827 in exon 28 leading to the substitution of a glutamine for a stop codon at amino acid 3206. A DNA sample from her dead affected mother was not available.

\section{R2639X}

This mutation is due to the modification of a $C>T$ at nucleotide position 8126 in exon 21, inducing a stop codon at amino acid 2639 instead of an arginine. A DNA sample from the patient's affected dead mother was not available. The disease was diagnosed in this man through the diagnosis of hypertension when he was 36 years old. He currently presents moderate renal failure at 44 years.

\section{0del 5}

This frameshift mutation results from the deletion of 5 nucleotides (CACGT), in exon 20, beginning at nucleotide position 8030 . This deletion should produce a prematurestop codon at amino acid 2659. This DNA variant was identified in a woman who started renal replacement therapy at 43 years of age.

The same DNA variant was found in her two affected children (diagnosed with the disease at 15 and 17years).

\section{NORMAL SEQUENCE}

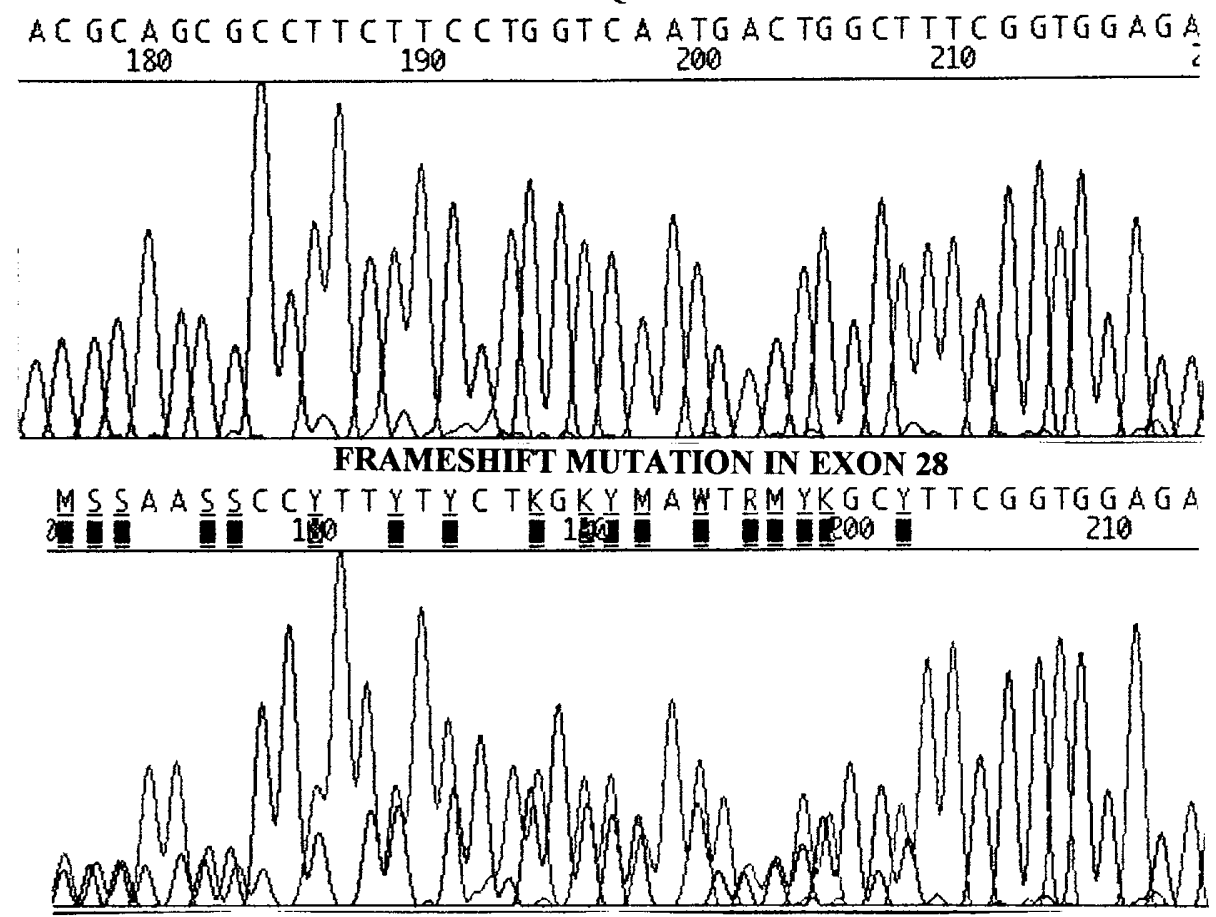

Figure 2 Sequencing data on the mutation 9867delT in exon 28 where a deletion of a T occurs leading to a frameshift mutation. 


\section{Y2336X}

The nucleotide change $\mathrm{C}>\mathrm{A}$ at nucleotide position 7219 leads to the appearance of a stop codon instead of a tyrosine at amino acid 2336. This nonsense mutation was identified in a woman who reached end-stage renal disease at 58 years. The same abnormal DGGE pattern was found in her affected son.

\section{R2329W}

This DNA variant in exon 16 results from a change of $C>$ T at nucleotide7196 leading to a substitution of an arginine (amino acid with basic side chain) for a tryptophan (nonpolar amino acid). The same nucleotide modification was also found in her affected sister but was absent in her three unaffected children. She started renal replacement therapy at 44 years. We did not find the same abnormal DGGE pattern in our series of normal chromosomes.

\section{IVS15 +2T > G}

This DNA variant is a splice mutation due to the substitution of $\mathrm{a} T$ for $\mathrm{a} G$ at nucleotide $7126+2$. This intronic mutation, causing the donor site invariant GT to become GG was described in a woman who was diagnosed with ADPKD at 56 years of age and needed renal replacement therapy from the age of 65 . The segregation of the disease with this DNA variant was confirmed because the same abnormality was found in her affected brother (ESRD at 65 years) and in her affected daughter, whereas a normal DGGE pattern was present in her other two unaffected children. This abnormal DGGE pattern was not found in our series of normal chromosomes.

\section{T2250M}

This DNA variant results from a change of $C>T$ at nucleotide6960 in exon 15, leading to a change from a threonine to a methionine. This DNA variant was found in three different patients from three different families. Unfortunately, only one family study has been done so far, in which the two unaffected daughters do not share the abnormal DNA variant of their affected mother. We did not find the same abnormal DGGE pattern in our series of normal chromosomes. This DNA variant is discussed below.

\section{Polymorphisms}

This screening also allowed us to describe several novel polymorphisms which are listed in Table2. These DNA variants were classified as polymorphisms either because they do not lead to the modification of the encoded amino acid, or by the non-segregation of the DNA variant with the disease in family studies, or because they were found in our cohort of normal chromosomes.

\section{Discussion}

In this study, we report additional disease-causing mutations detected in the PKD 1, identified within the duplicated region of the PKD 1. It concerns mainly frameshift or stop mutations which are clearly pathogenic changes.

We have attempted to amplify the whole region located from the $3^{\prime}$ end of exon 15 to exon 34 (about $13.9 \mathrm{~Kb}$ ), under conditions previously described by Watnick et al, ${ }^{32}$ with a modification of the $3^{\prime}$ primer, technically feasible with our rTtH enzyme, but the long polypyrimidine tract located in intron 21 probably prevented us from achieving this aim. ${ }^{12}$ Thus we had to perform two separate LR amplifications to generate specific templates as had been previously undertaken by Watnick. ${ }^{32,38}$ As in our first study within the $3^{\prime}$ region, DGGE screening was successfully applied to scan for mutations in that part of the repeated region of the PKD1 gene. Indeed, the DGGE approach has been particularly effective (approaching 100\%) in terms of the mutation screening of some reported genes. ${ }^{41}$

In this study we have identified three nonsense mutations, two frameshift mutations, two possible missense mutations, and one splicing mutation. For the missense mutation R2329W, the segregation of the disease with the DNA

Table 2 Polymorphisms detected in the PKD1 gene

\begin{tabular}{|c|c|c|c|}
\hline Polymorphism & Exon & Amino acid change & Nucleotide change \\
\hline IVS $34+20$ & Intron 34 & & $\mathrm{G} \rightarrow \mathrm{A}$ at $10707+20$ \\
\hline IVS $31+7$ & Intron 31 & & $A \rightarrow G$ at $10378+7$ \\
\hline P3193L & 28 & Proline $>$ Leucine & $\mathrm{C} \rightarrow \mathrm{T}$ at NT 9789 \\
\hline P3110P & 26 & None & $\mathrm{T} \rightarrow \mathrm{C}$ at NT 9541 \\
\hline V3090V & 26 & None & $\mathrm{C} \rightarrow \mathrm{T}$ at NT 9481 \\
\hline F3066L & 25 & Phenylalanine $>$ Leucine & $\mathrm{T} \rightarrow \mathrm{C}$ at NT 9407 \\
\hline V3065V & 25 & None & $\mathrm{G} \rightarrow \mathrm{C}$ at NT 9406 \\
\hline IVS 25-17 & Intron 24 & & $A \rightarrow G$ at $9160-17$ \\
\hline L2481L & 18 & None & $\mathrm{C} \rightarrow \mathrm{T}$ at NT 7652 \\
\hline IVS18-27 & Intron 17 & & $\mathrm{C} \rightarrow \mathrm{A}$ at $7421-27$ \\
\hline IVS18-10 & Intron 17 & & $C \rightarrow A$ at $7421-10$ \\
\hline L2389L & 17 & None & $\mathrm{T} \rightarrow \mathrm{C}$ at $\mathrm{NT} 7376$ \\
\hline Y2379C & 17 & None & $\mathrm{A} \rightarrow \mathrm{G}$ at NT 7347 \\
\hline G2309G & 16 & None & $\mathrm{C} \rightarrow \mathrm{T}$ at $\mathrm{NT} 7138$ \\
\hline IVS 16-9 & 16 & & $\mathrm{G} \rightarrow \mathrm{A}$ at $7127-9$ \\
\hline
\end{tabular}


variation and its absence in our series of normal chromosomes is suggestive of its likely pathogenicity. Indeed, the substitution of a positively charged arginine for a neutral residue of tryptophan might be significant. For T2250M one might also hypothesise that the introduction of a methionine instead of a threonine could well affect the secondary structure of the molecule which could disrupt $\alpha$ helixes and $\beta$ stands. Due to the lack of functional evidence and since the entire length of the gene was not screened for mutation, it is difficult to establish with any great certainty the pathogenicity of such variants. Thus, it is not easy to conclude whether these substitutions are pathogen ic mutations or very rare polymorphisms. However, for T2250M , these amino-acid changes have been reported as a missense mutation elsewhere in the PKD1 gene (M 3677T in exon 38). For the very likely splice mutation - IVS15 + 2 T > G, -, one may predict that the disruption of the invariant site will affect this splice site.
If we take into account our additional PKD 1 mutations reported in this study, about 75 mutations have al ready been identified, listed in Table3. Most of them are point mutations, resulting in a truncated protein linked either to a nonsense mutation occurring within the gene or a frameshift mutation inducing a premature stop codon. The mutations documented in PKD 1 are spread throughout the gene from exon 2 to exon 46. Nevertheless, to date there has been no report of the analysis of exon 1 . Although no clear hot spot for mutations is apparent, some clustering can be observed. A large number of mutations (almost one-third) lies within exons 44 to 46 . The reason may be because most reported studies dealing with the screening of mutations were performed within the $3^{\prime}$ unique region of the gene, and the primers used were described at an early stage. This could be responsible for a bias in the analysis. However, it could be equally linked to the fact that the $3^{\prime}$ end is a functionally important region involved in the disease physiopathology.

Table 3 Summary of PKD1 gene mutations described to date

\begin{tabular}{|c|c|c|c|c|c|}
\hline Mutation & Location & References & Mutation & Location & References \\
\hline \multicolumn{3}{|l|}{ Nonsense } & \multicolumn{3}{|l|}{ Deletions } \\
\hline W1814X & Exon 15 & Roelfsema ${ }^{26}$ & g18177-21076 del3kb & Intron-Exon 5 & Thomas $^{23}$ \\
\hline Q1922X & Exon 15 & Thomas $^{23}$ & 4077delT & Exon 15 & Roelfsema 26 \\
\hline Y2336X & Exon 16 & Present study & 4247del2 & Exon 15 & Roelfsema ${ }^{26}$ \\
\hline R2639X & Exon 21 & Present study & 5225 delA & Exon 15 & Roelfsema 26 \\
\hline Q2900X & Exon 23 & Roelfsema ${ }^{26}$ & 6434-6461del28 & Exon 15 & Thomas $^{23}$ \\
\hline E3020X & Exon 25 & Peral ${ }^{20}$ & 6785del17 & Exon 15 & Roelfsema ${ }^{26}$ \\
\hline Q3206X & Exon 28 & Present study & 8030 del5 & Exon 20 & Present study \\
\hline Q3474X & Exon 34 & Perrichot $^{24}$ & 8657delC & Exon 23 & Peral $^{20}$ \\
\hline Q3513X & Exon 35 & Peral ${ }^{20}$ & 9299delC & Exon 25 & Peral $^{20}$ \\
\hline Y3818X & Exon 41 & Peral $^{10}$ & 9867delT & Exon 28 & Present study \\
\hline Q3820X & Exon 41 & Personal communication & IVS31+25del19 & Intron 31 & Peral 20 \\
\hline Q3837X & Exon 41 & Peral $^{19}$ & 10262del2kb & Intron 30-34 & European Consortium² \\
\hline Q4010X & Exon 44 & Daniells $^{17}$ & 11341 delC & Exon 38 & Turco 29 \\
\hline W4011X & Exon 44 & Roelfsema ${ }^{26}$ & 11457 del15 & Exon 39 & Peral $^{19}$ \\
\hline R4020X & Exon 44 & Rosetti ${ }^{27}$ & IVS39+266del72 & Intron 39-Exon 40 & Peral ${ }^{19}$ \\
\hline E4024X & Exon 44 & Daniells ${ }^{17}$ & 10708 del15,5kb & Intron 34-Exon 46 & European Consortium² \\
\hline Q4059X & Exon 45 & Daniells ${ }^{28}$ & IVS43+17del18 & Intron 43 & Peral $^{18}$ \\
\hline C4086X & Exon 45 & Neophytou ${ }^{25}$ & 12262 del 2 & Exon 44 & Daniells ${ }^{17}$ \\
\hline W4139X & Exon 45 & Perrichot $^{24}$ & 12739delA & Exon 46 & Peral $^{20}$ \\
\hline Y4126X & Exon 45 & Turco 30 & 12801del28 & Exon 46 & Badenas $^{21}$ \\
\hline Q4124X & Exon 45 & Badenas, $^{21}$ Daniells ${ }^{28}$ & & & \\
\hline Y4236X & Exon 46 & Personal communication & Insertions & & \\
\hline \multirow[t]{2}{*}{$\mathrm{R} 4227 \mathrm{X}$} & \multirow[t]{3}{*}{ Exon 46} & \multirow[t]{3}{*}{ Peral $^{19}$} & 4898-4899insT & Exon 15 & Thomas $^{23}$ \\
\hline & & & 10947insT & Exon 36 & Peral $^{19}$ \\
\hline M issense & & & 11284insT & Exon 38 & Perrichot $^{24}$ \\
\hline R324L & Exon 5 & Thomas $^{23}$ & 11285 insC & Exon 38 & Perichot $^{24}$ \\
\hline L845S & Exon 11 & Thomas $^{23}$ & 11549ins10 & Exon 40 & Turco $^{30}$ \\
\hline T2250M & Exon 15 & Present study & $12187 i n s 9$ & Exon 43 & Perrichot $^{24}$ \\
\hline R2329W & Exon 16 & Present study & 12416 ins 20 & Exon 45 & Daniells $s^{28}$ \\
\hline L2993P & Exon 25 & Peral ${ }^{20}$ & 12511 insG & Exon 45 & Daniells $s^{28}$ \\
\hline Q3016R & Exon 25 & Peral ${ }^{20}$ & 12714 ins23 & Exon 46 & Perrichot ${ }^{24}$ \\
\hline V3375M & Exon 31 & Koptides 22 & & & \\
\hline L3510V & Exon 35 & Peral ${ }^{20}$ & Splicing & & \\
\hline R4153C & Exon 45 & Perrichot ${ }^{24}$ & IVS41 +2ins3 & Intron 41 & Personal communication \\
\hline R4135G & Exon 45 & Perrichot $^{24}$ & IVS44 +1 G>C & Intron 44 & European Consortium ${ }^{2}$ \\
\hline Q4224P & Exon 46 & Badenas $^{21}$ & IVS44-1 G>C & Intron 44 & Badenas $^{21}$ \\
\hline $\mathrm{R} 4275 \mathrm{~W}$ & Exon 46 & Badenas $^{21}$ & IVS45 -1 G>A & Intron 45 & Badenas $^{21}$ \\
\hline
\end{tabular}


This region in particular binds the $\mathrm{G}$ protein activation peptide recently described. ${ }^{42}$ This highly evolutionary conserved region contains a binding domain for the heterotrimeric $\mathrm{G}$ protein, suggesting that the $\mathrm{C}$ terminal cytosolic domain of polycystin-1 may function by initiating $G$ protein coupled signal transduction and directly interacts with signalling proteins. Flanking this peptide, the presence of serine and tyrosine phosphorylation sites has been reported, ${ }^{42,43}$ which could also be of physiological relevance. This region is equally the site of the coiled-coil domain, located in exon $46 .{ }^{44}$ This domain of polycystin-1 binds specifically to the $C$ terminus of the PKD2 product suggesting that PKD 1 and PKD 2 may be partners in a common signalling cascade; this could explain the similar clinical presentation of PKD 1 and PKD 2 diseases. Some clustering is also observed in exon 15 where some $15 \%$ of mutations were reported. This could be partly explained by the large size of exon 15 (more than $3.5 \mathrm{~kb}$ ). The other explanation is the functional relevance of this region containing the 'immunoglobulin-like' domains which may be involved in protein-protein interactions or cell adhesion mechanisms as suggested in Bycroft's recent work. ${ }^{45}$ The detection of mutations disrupting one of these functionally important interactions could help in improving our knowledge of the physiopathology of the disease.

Most of the reported mutations in the gene appear to be unique (specific) to each family with some exceptions to this rule. The recurrence of Q4041X in different countries with different ancestral origins, ${ }^{31}$ has been previously debated as well as the several descriptions of R4227X ${ }^{19}{ }^{19} 4275 W^{21}$ and Q4124X ${ }^{21,28}$ The T2250M variation described in this report could be the fifth recurrent mutation if further analyses, such as geneaological studies, analysis of the complete coding sequence, and comparison of the haplotypes, confirm that the three affected patients present different ancestral origins.

Overall, previous studies with a limited number of identified mutations have emphasised that no clear correlation between the severity of the renal disease and the type or position of the mutation is obvious ${ }^{20}$ except for TSC2-PKD 1 contiguous gene syndrome. ${ }^{46}$ Three families with 'clinical anticipation' presenting very early onset cases have also been reported. ${ }^{10,11,24}$

Despite intense screening using various approaches, the mutation detection rate remains relatively low, 30-36\% maximum, ${ }^{23,24}$ in contrast to the high mutation detection rate (85\%) in PKD 2 families reported by R Torra et al. ${ }^{47}$ In our series this rate is much lower but we have not yet screened the first 15 exons. Considering these data, it could be hypothesised that most of the mutations could be localised either in the PKD1 promoter, in exon 1 or in some intronic regions that have not yet been correctly analysed. Efforts must be made to screen the whole coding and non-coding areas of the PKD 1 gene, which could help us to elucidate the physiopathology of the disease. Moreover, the analysis of all genetic defects is of key importance in respect of successful development of therapeutic approaches. The duplicated regions of the PKD 1 gene, the number of exons (46), the length of the coding sequence ( $14 \mathrm{~kb}$ mRNA) and the GC rich sequence are strong arguments which contribute to difficulties in systematically analysing the gene for ADPKD diagnosis, using current techniques. Until new techniques are developed, such as DNA chips, or a functional assay implemented, molecular ADPKD diagnosis will still be mostly performed using linkage disequilibrium analysis.

\section{Acknowledgements}

Support was provided by grants from the INSERM (CRI no 96-07) and Projets Hospitaliers de Recherche Clinique (PHRC 1996). This work was presented in a poster session at the 30th Annual Meeting of the International Society of Nephrology, Buenos Aires, May 1999, and to the American Society of Human Genetics, San Francisco, in October 1999. We also thank the nephrologists Dr Joyeux, Dr Toulet and Dr Islam who supplied clinical information on their patients.

\section{References}

1 Peters DJ, Sandkuijl LA: Genetic heterogeneity of polycystic kidney disease in Europe. Contrib Nephrol 1992; 97: 128-139.

2 European Polycystic Kidney Disease Consortium: The polycystic kidney disease 1 gene encodes a $14 \mathrm{~kb}$ transcript and lies within a duplicated region on chromosome16. Cell 1994; 77: 881-894.

3 Mochizuki T, Wu G, Hayashi T et al: PKD2, a gene for polycystic kidney disease that encodes an integral membrane protein. Science 1996: 272: 1339-1342.

4 Kimberling WJ, Kumar R, Gabow PA eta al: Autosomal dominant polycystic kidney disease: localisation of the second gene to chromosome4q13-23. Genomics 1993; 18: 467-472.

5 Daoust MC, Reynolds DM, Bichet DG et al: Evidence for a third genetic locus for autosomal dominant polycystic kidney disease. Genomics 1995; 25: 733-736.

6 Gabow PA: Definition and natural history of autosomal dominant polycystic kidney disease in polycystic kidney disease. Oxford University Press Inc.: NY. Clinical Nephrology Series 1996; 332-355.

7 Ravine D, Walker RG, Gibson RN et al: Phenotype and genotype heterogeneity in autosomal dominant polycystic kidney disease. Lancet 1992; 340: 1330-1333.

8 Hateboer N, Lazarou A, Williams A et al: Familial phenotype differences in PKD1. Kidney Int 1999; 56: 34-40.

9 Hateboer N, Dijk MA, Bogdanova N et al: Comparison of phenotypes of polycystic kidney disease types 1 and 2. European PKD1-PKD2 Study Group. Lancet 1999; 353: 103-107.

10 Peral B, Ong ACM, San Millan JL et al: A stable, nonsense mutation associated with a case of infantile onset polycystic kidney disease1 (PKD1). Hum Mol Genet 1996; 5: 539-542.

11 Torra R, Badenas C, Darnell A et al: Autosomal dominant polycystic kidney disease with anticipation and Caroli's disease associated with PKD1 mutation. Kidney Int 1997; 52: 33-38.

12 Oian F, Watnick T, Onuchic LF et al: The molecular basis of focal cyst formation in human autosomal dominant polycystic kidney disease type1. Cell 1996; 87: 979-987.

13 Brasier JL, Henske EP: Loss of the polycystic kidney disease (PKD1) region of chromosome16p13 in renal cyst cells supports a lossof-function model for cyst pathogenesis. J Clin Invest 1997; 99: 194-199.

14 Torra R, Badenas C, San Millan JL et al: A loss-of-function model for cystogenesis in human autosomal dominant polycystic kidney disease type2. Am J Hum Genet 1999; 65: 345-352. 
15 Pei Y, Watnick T, HeN et al: Somatic PKD2 mutations in individual kidney and liver cysts support a two-hit model of cystogenesis in type 2 autosomal polycystic kidney disease. J Am Soc N ephrol 1999; 10: $1524-1529$.

16 Koptides M, Hadjimichael C, Koupepidou P et al: Germinal and somatic mutations in the PKD2 gene of renal cysts in autosomal dominant polycystic kidney disease. Hum Mol Genet 1999; 3: 509-513.

17 Daniells C, Maheshwar MM, Lazarou L et al: Novel and recurrent mutations in the PKD1 (polycystic kidney disease). Gene Hum Genet 1998; 102: 216-220.

18 Peral B, Gamble V, San Millan JL et al: Splicing mutations of the polycystic kidney disease1 (PKD1) gene induced by intronic deletion. Hum Mol Genet 1995; 4: 569-574.

19 Peral B, San Millan JL, Ong ACM et al: Screening the 3' region of the polycystic kidney disease1 (PKD1) gene reveals six novel mutations. Am J Hum Genet 1996; 58: 86-96.

20 Peral B, Gamble V, Strong C et al: Identification of mutations in the duplicated region of the polycystic kidney disease-1 (PKD1) gene by a novel approach. Am J Hum Genet 1997; 60: 1399-1410.

21 Badenas C, Torra R, San Millan JL et al: Mutational analysis within the 3' region of the PKD1 gene. Kidney Int 1999; 55: 1225-1233.

22 Koptides M, Constantinides R, Kyriakides $G$ et al: Loss of heterozygosity in polycystic kidney disease with a missense mutation in the repeated region of PKD1. Hum Genet 1998; 103: 709-717.

23 Thomas R, McConnell R, Whittacker J et al: Identification of mutations in the repeated part of the autosomal dominant polycystic kidney disease typel gene, PKD1, by long-range PCR. Am J Hum Genet 1999; 65: 39-49.

24 Perrichot $\mathrm{R}$, Mercier $\mathrm{B}$, Simon $\mathrm{P}$ et al: DGGE screening of PKD1 gene reveals novel mutations in a large cohort of 146 unrelated patients. Hum Genet 1999; 105: 231-239.

25 Neophytou P, Constantinides R, Lazarou A et al: Detection of a novel nonsense mutation and an intragenic polymorphism in the PKD1 gene of a Cypriot family with autosomal dominant polycystic kidney disease. Hum Genet 1996; 98: 437-442.

26 Roelfsema JH, Spruit L, Saris JJ et al: Mutation detection in the repeated part of PKD1 gene. Am J Hum Genet 1997; 61: 1044-1052.

27 Rossetti S, Bresin E, Restagno G et al: Autosomal dominant polycystic kidney disease (ADPKD) in an Italian family carrying a novel nonsense mutation and two missense changes in exon 44 and 45 of the PKD1 gene. Am J Hum Genet 1996; 65: 155-159.

28 Daniells C, Maheshwar MM, Lazarou L et al: Gene symbol: PKD1 disease: polycystic kidney disease. Hum Genet 1998; 102: 127.

29 Turco A, Bresin E, Rossetti S et al: Molecular genetic investigations in autosomal dominant polycystic kidney disease. Contrib Nephrol 1997; 122: 53-57.

30 Turco A, Rosetti S, Bresin E et al: Three novel mutations of the PKD1 gene in Italian families with autosomal dominant polycystic kidney disease. Hum Mutat 1997; 10: 164-167.

31 Torra R, Badenas C, Peral B et al: Recurrence of the PKD 1 nonsense mutation Q4041X in Spanish, Italian and British families. Hum Mutat 1998; S117-S120.
32 Watnick T, Pontiek KB, Cordal TM et al: An unusual pattern of mutation in the duplicated portion of PKD 1 is revealed by use of a novel strategy for mutation detection. Hum Mol Genet 1997; 6: 1473-1481.

33 Roelfsema JH, Peters DJM, Breuning M: Detection of translation terminating mutations in the PKD 1 gene. Nephrol Dial Transplant 1996; 11: 5-9.

34 Chauveau D, Rosetti S, Strmecki $L$ et al: Mutation detection at PKD1 by PTT and direct sequencing. J Am Soc Nephrol 1998; 9: 372A.

35 Bear JC, McManamon P, Morgan J et al: Age at clinical onset and at ultrasonographic detection of adult polycystic kidney disease: data for genetic counselling. Am J Med Genet 1984; 18: 45-53.

36 Ravine D, Gibson RN, Walker RG, Sheffield LJ, Kinkaid-Smith P, Danks DM: Evaluation of ultrasonographicdiagnostic criteria for autosomal polycystic kidney disease1. Lancet 1994; 343: 824-827.

37 Miller SA, Dykes DD, Polesky HF: A simple salting out procedure for extracting DNA from human nucleoled cells. Nucleic Acids Res 1988; 16: 1215

38 Watnick T, Torres V, Gandolph MA et al: Somatic mutation in individual liver cysts supports a two hit model of cystogenesis in autosomal dominant polycystic kidney disease. Mol Cell 1998; 2: 247-251.

39 Antonarakis SE, Nomenclature Working Group: Recommendations for nomenclature system for human gene mutations. Hum Mutat 1998; 11: 1-3.

40 Hughes J, Ward CJ, Peral B et al: The polycystic kidney disease 1 (PKD1) gene encodes a novel protein with multiple cell recognition domains. Nat Genet 1995; 10: 151-160.

41 Macek M, Mercier B, Mackova A et al: Sensitivity of denaturing gradient gel electrophoresis technique in detection of known mutations in the CFTR gene. Hum Mutat 1997; 9: 136-147.

42 Parnell SC, Magenheimer, Rankin CA et al: The polycystic kidney disease 1 protein, polycystine-1, binds and activate heterotrimeric G-protein in vitro. Biochem Biophys Res Comm 1998; 251: 625-631.

$43 \mathrm{Li} \mathrm{H}$, Geng L, Burrow $\mathrm{C}$ et al: Identification of phosphorylation sites in PKDl-encoded protein C-terminal domain. Biochem Biophys Res Com 1999; 259: 356-363.

44 Qian F, Germino FJ, Cai Y et al: PKD1 interacts with PKD2 through a probable coiled-cell domain. Nat Genet 1997; 16: 179-183.

45 Bycroft M, Bateman A, Clarke J et al: The structure of a PKD domain from polycystin-1: implications for polycystic kidney disease. EMBO J 1999; 18: 297-305.

46 Brook-Carter PT, Peral B, Ward CJ et al: Deletion of the TSC2 and PKD1 genes associated with severe infantile polycystic kidney disease. A contiguous gene syndrome. Nature 1994; 8: 328-332.

47 Torra R, Vibiray M, Telleria D et al: Seven novel mutations of the PKD gene in families with autosomal dominant polycystic kidney disease. Kidney Int 1999; 56: 28-33.

48 Turco A, Rossetti S, Bresin E et al: A novel nonsense mutation in the PKD 1 gene (C3817T) is associated with autosomal dominant polycystic kidney disease (ADPKD) in a large three-generation Italian family. Hum Mol Genet 1995; 4: 1331-1335. 